\title{
Otimização do meio e condições de cultura do Rhodococcus erythropolis ATCC4277
}

\author{
D. TODESCATO ${ }^{1}$, D. G. D. ROCCA ${ }^{1}$, D. MAASS ${ }^{1}$, D. OLIVEIRA ${ }^{1}$, S. M. A. \\ GUELLI U. SOUZA ${ }^{1}$, A. A. ULSON DE SOUZA ${ }^{1}$
}

${ }^{1}$ Universidade Federal de Santa Catarina, Departamento de Engenharia Química e de Alimentos

E-mail para contato: augusto@enq.ufsc.br

\begin{abstract}
RESUMO - A bactéria Rhodococcus erythropolis encontra-se em voga por suas inúmeras aplicações, principalmente na produção de biossurfactantes e em processos de remoção de enxofre e nitrogênio do petróleo e seus derivados. Portanto, a otimização do meio nutritivo e das condições de cultura do Rhodococcus erythropolis visa obter uma maior quantidade de células com o menor gasto energético, para posterior emprego dessa bactéria em outros processos biotecnológicos. Para isso foi foram avaliados o efeito das variáveis como concentração de substrato (extrato de levedura), concentração de nutriente $\left(\mathrm{CaCO}_{3}\right)$, agitação e temperatura sobre o crescimento celular através de um planejamento experimental $2^{4}$ com pontos axiais. Os ensaios foram conduzidos com concentração de glicose e extrato de malte fixa em 2,0 $\mathrm{g} \mathrm{L}^{-1}$ e 5,0 $\mathrm{g} \mathrm{L}^{-1}$, respectivamente, e o tempo de crescimento foi de 18 horas. De acordo com os dados obtidos, os pontos críticos ou estacionários, onde se obteve o máximo de crescimento celular $\left(5,10 \mathrm{~g} \mathrm{~L}^{-1}\right)$, correspondem às concentrações de extrato de levedura de 6,15 $\mathrm{g} \mathrm{L}^{-1}$, de $\mathrm{CaCO}_{3}$ de $1,16 \mathrm{~g} \mathrm{~L}^{-1}$, temperatura de $23,7{ }^{\circ} \mathrm{C}$ e agitação de $180 \mathrm{rpm}$.
\end{abstract}

\section{INTRODUÇÃO}

As bactérias do gênero Rhodococcus têm como características a forma de bastonete, são gram-positivas e aeróbicas. Normalmente crescem bem a temperaturas entre 30 e $37^{\circ} \mathrm{C}$ e nos meios nutritivos sintéticos de laboratório (Sanchéz et al, 2004).

Há relatos de um grande número de desalogenações, desidrogenações, epoxidações, hidrólises, hidroxilações, oxidações, e, principalmente, desulfurizações, denitrogenações e produção de biossurfactante realizadas por células ou enzimas do Rhodococcus erythropolis. Essa grande variedade de bioconversões e degradações justificam plenamente a aplicação prospectiva desta bactéria em processos biotecnológicos (Carvalho \& Fonseca, 2005; Dinamarca et al, 2014; Dinamarca et al, 2010; Torres et al, 2011).

A otimização do meio de cultivo e das condições de fermentação é considerado um dos passos mais importantes no desenvolvimento de processos biotecnológicos economicamente viáveis. Pois através desse método é possível selecionar os nutrientes 
apropriados e as condições ótimas de cultivo que proporcionem um crescimento celular máximo. Esse ponto crítico melhora o rendimento do processo fermentativo, sem aumentar o custo de produção (Huang et al, 2008; Vaidya et al, 2009).

$\mathrm{O}$ presente estudo busca desenvolver uma condição ideal de crescimento das células do Rhodococcus erythropolis ATCC 4277 utilizando o meio nutritivo sintético Yeast Malt (YM). Para isso foi avaliada a influência de fatores como concentração de substrato (extrato de levedura), concentração de nutriente $\left(\mathrm{CaCO}_{3}\right)$, agitação e temperatura sobre o crescimento celular através de um planejamento experimental $2^{4}$ com pontos axiais.

\section{MATERIAIS E MÉTODOS}

\subsection{Micro-organismo}

O micro-organismo utilizado neste estudo foi uma bactéria mesófila, Rhodococcus erythopolis ATCC4277 adquirida da Fundação Tropical de Pesquisas e Tecnologia André Tosello, Campinas, São Paulo.

\subsection{Inoculo}

$\mathrm{O}$ inoculo de $50 \mathrm{~mL}$ foi preparado a partir de extrato de levedura 4,0 g.L $\mathrm{L}^{-1}$, glicose $\left(\mathrm{C}_{6} \mathrm{H}_{12} \mathrm{O}_{6}\right)$ 4,0 g. $\mathrm{L}^{-1}$, carbonato de cálcio $\left(\mathrm{CaCO}_{3}\right)$ 2,0 g. $\mathrm{L}^{-1}$ e extrato de malte $\left(\mathrm{C}_{12} \mathrm{H}_{22} \mathrm{O}_{11}\right)$ 10,0 g.. $\mathrm{L}^{-1}$. A ele foi adicionada uma alça de platina de bactérias, que permaneceram por $24 \mathrm{~h}$, a uma velocidade de 150 rotações por minuto (rpm) e a uma temperatura de $28^{\circ} \mathrm{C}$ - em fase de adaptação.

Para realizar o acompanhamento do crescimento celular utilizou-se uma curva de calibração células de Rhodococcus erythropolis, onde o comprimento de onda que apresentou maior absorbância foi o de $600 \mathrm{~nm}$.

\subsection{Meio de crescimento}

Foram transferidos 5,0 mL do inoculo para cada frasco Erlenmeyer contendo $100 \mathrm{~mL}$ de meio de crescimento esterilizado. Neste instante, retirou-se a primeira alíquota do meio de crescimento e leu-se sua absorbância no espectrofotômetro $(\lambda=600 \mathrm{~nm})$.

Os ensaios foram conduzidos com concentração de glicose e extrato de malte fixa em 2,0 g.L. $\mathrm{L}^{-1}$ e 5,0 g.L $\mathrm{L}^{-1}$, respectivamente. O período de análise foi fixado em $18 \mathrm{~h}$ (período em que todos os experimentos atingiram a fase estacionária).

Por serem quatro fatores variáveis, optou-se por um planejamento experimental $2^{4}$, com pontos axiais e com triplicatas no ponto central, totalizando 27 experimentos, como resposta a concentração celular.

No estudo do processo, em batelada, foram modificadas quatro variáveis:

(A) Concentração de levedura (g.L $\left.\mathrm{L}^{-1}\right)$

(B) Concentração de carbonato de cálcio $\left(\mathrm{g} . \mathrm{L}^{-1}\right)$

(C) Temperatura $\left({ }^{\circ} \mathrm{C}\right)$

(D) Agitação (rpm) 
Definiram-se os níveis de variação codificados como -2, -1, 0, +1 e +2 - para cada um dos fatores em estudo. As variáveis e seus respectivos níveis de variação são mostrados na Tabela 1.

Tabela 1. Fatores e seus respectivos níveis estudados na otimização da concentração celular para o planejamento estrela.

\begin{tabular}{ccccccc}
\hline Fatores & Nível & $\mathbf{- 2}$ & $\mathbf{- 1}$ & $\mathbf{0}$ & $\mathbf{+ 1}$ & $\mathbf{+ 2}$ \\
\hline $\mathrm{A}$ & Extrato de Levedura $\left(\mathrm{g} \mathrm{L}^{-1}\right)$ & 2,0 & 4,0 & 6,0 & 8,0 & 10 \\
$\mathrm{~B}$ & $\mathrm{CaCO}_{3}\left(\mathrm{~g} \mathrm{~L}^{-1}\right)$ & 0,2 & 0,6 & 1,0 & 1,4 & 1,8 \\
$\mathrm{C}$ & ${\text { Temperatura }\left({ }^{\circ} \mathrm{C}\right)}_{\mathrm{D}}$ & 20 & 22 & 24 & 26 & 28 \\
$\mathrm{D}$ & Agitação $(\mathrm{rpm})$ & 130 & 160 & 190 & 220 & 250 \\
\hline
\end{tabular}

\section{RESULTADOS E DISCUSSÕES}

Os resultados da avaliação quanto ao crescimento celular do Rhodococcus erythropolis, bem como cada condição empregada podem ser observados na Tabela 2.

Tabela 2. Planejamento experimental $2^{4}$ com pontos axiais para otimização das condições experimentais para o crescimento de Rhodococcus erythropolis.

\begin{tabular}{cccccc}
\hline Experimento & $\mathbf{A}$ (g/L) & $\mathbf{B}$ (g/L) & $\mathbf{C}\left({ }^{\circ} \mathbf{C}\right)$ & $\mathbf{D}$ (rpm) & $\begin{array}{c}\text { Concentração } \\
\text { celular (g/L) }\end{array}$ \\
\hline 1 & $(-1) 4,0$ & $(-1) 0,6$ & $(-1) 22$ & $(-1) 160$ & 3,61 \\
2 & $(1) 8,0$ & $(-1) 0,6$ & $(-1) 22$ & $(-1) 160$ & 2,29 \\
3 & $(-1) 4,0$ & $(1) 1,4$ & $(-1) 22$ & $(-1) 160$ & 4,17 \\
4 & $(1) 8,0$ & $(1) 1,4$ & $(-1) 22$ & $(-1) 160$ & 4,27 \\
5 & $(-1) 4,0$ & $(-1) 0,6$ & $(1) 26$ & $(-1) 160$ & 3,51 \\
6 & $(1) 8,0$ & $(-1) 0,6$ & $(1) 26$ & $(-1) 160$ & 3,06 \\
7 & $(-1) 4,0$ & $(1) 1,4$ & $(1) 26$ & $(-1) 160$ & 3,37 \\
8 & $(1) 8,0$ & $(1) 1,4$ & $(1) 26$ & $(-1) 160$ & 2,32 \\
9 & $(-1) 4,0$ & $(-1) 0,6$ & $(-1) 22$ & $(1) 220$ & 1,60 \\
10 & $(1) 8,0$ & $(-1) 0,6$ & $(-1) 22$ & $(1) 220$ & 3,16 \\
11 & $(-1) 4,0$ & $(1) 1,4$ & $(-1) 22$ & $(1) 220$ & 1,75 \\
12 & $(1) 8,0$ & $(1) 1,4$ & $(-1) 22$ & $(1) 220$ & 3,66 \\
13 & $(-1) 4,0$ & $(-1) 0,6$ & $(1) 26$ & $(1) 220$ & 3,29 \\
14 & $(1) 8,0$ & $(-1) 0,6$ & $(1) 26$ & $(1) 220$ & 3,65 \\
15 & $(-1) 4,0$ & $(1) 1,4$ & $(1) 26$ & $(1) 220$ & 2,89 \\
16 & $(1) 8,0$ & $(1) 1,4$ & $(1) 26$ & $(1) 220$ & 2,13 \\
17 & $(-2) 2,0$ & $(0) 1,0$ & $(0) 24$ & $(0) 190$ & 2,17 \\
18 & $(2) 10$ & $(0) 1,0$ & $(0) 24$ & $(0) 190$ & 3,95 \\
19 & $(0) 6,0$ & $(-2) 0,2$ & $(0) 24$ & $(0) 190$ & 3,07 \\
20 & $(0) 6,0$ & $(2) 1,8$ & $(0) 24$ & $(0) 190$ & 4,82 \\
21 & $(0) 6,0$ & $(0) 1,0$ & $(-2) 20$ & $(0) 190$ & 2,51 \\
22 & $(0) 6,0$ & $(0) 1,0$ & $(2) 28$ & $(0) 190$ & 3,58 \\
23 & $(0) 6,0$ & $(0) 1,0$ & $(0) 24$ & $(-2) 130$ & 3,66 \\
24 & $(0) 6,0$ & $(0) 1,0$ & $(0) 24$ & $(2) 250$ & 3,83 \\
25 & $(0) 6,0$ & $(0) 1,0$ & $(0) 24$ & $(0) 190$ & 5,27 \\
26 & $(0) 6,0$ & $(0) 1,0$ & $(0) 24$ & $(0) 190$ & 5,08 \\
27 & $(0) 6,0$ & $(0) 1,0$ & $(0) 24$ & $(0) 190$ & 4,77 \\
\hline
\end{tabular}


Os valores da concentração celular de cada composição de meio foram muito variados, ficando entre $1,60 \mathrm{~g} \mathrm{~L}^{-1}$ e $5,27 \mathrm{~g} \mathrm{~L}^{-1}$. A Tabela 3 , mostra a análise de variância (ANOVA) do modelo obtido.

Tabela 31. Tabela análise da variância para o crescimento celular.

\begin{tabular}{cccccc}
\hline Fatores & SS & df & MS & F & $\boldsymbol{p}$ \\
\hline (1) Concentração Ext. Levedura (L) & 0,637 & 1 & 0,637 & 1,35 & 0,266 \\
Concentração Ext. Levedura (Q) & $\mathbf{6 , 7 4 2}$ & $\mathbf{1}$ & $\mathbf{6 , 7 4 2}$ & $\mathbf{1 4 , 3 5}$ & $\mathbf{0 , 0 0 2}$ \\
(2) Concentração CaCO3 (L) & 0,630 & 1 & 0,630 & 1,34 & 0,269 \\
Concentração CaCO3 (Q) & $\mathbf{2 , 4 7 9}$ & $\mathbf{1}$ & $\mathbf{2 , 4 7 9}$ & $\mathbf{5 , 2 8}$ & $\mathbf{0 , 0 4 0}$ \\
(3) Temperatura (L) & 0,142 & 1 & 0,142 & 0,30 & 0,591 \\
Temperatura (Q) & $\mathbf{6 , 8 3 2}$ & $\mathbf{1}$ & $\mathbf{6 , 8 3 2}$ & $\mathbf{1 4 , 5 4}$ & $\mathbf{0 , 0 0 2}$ \\
(4) Agitação (L) & 0,710 & 1 & 0,710 & 1,51 & 0,242 \\
Agitação (Q) & $\mathbf{3 , 2 6 0}$ & $\mathbf{1}$ & $\mathbf{3 , 2 6 0}$ & $\mathbf{6 , 9 4}$ & $\mathbf{0 , 0 2 1}$ \\
Interação entre 1 e 2 & 0,000 & 1 & 0,000 & 0,00 & 0,985 \\
Interação entre 1 e 3 & 1,076 & 1 & 1,076 & 2,29 & 0,155 \\
Interação entre 1 e 4 & 2,095 & 1 & 2,095 & 4,46 & 0,056 \\
Interação entre 2 e 3 & $\mathbf{2 , 2 4 2}$ & $\mathbf{1}$ & $\mathbf{2 , 2 4 2}$ & $\mathbf{4 , 7 7}$ & $\mathbf{0 , 0 4 9}$ \\
Interação entre 2 e 4 & 0,536 & 1 & 0,536 & 1,14 & 0,306 \\
Interação entre 3 e 4 & 0,936 & 1 & 0,936 & 1,99 & 0,183 \\
Erros & 5,635 & 12 & 0,469 & & \\
Total SS & 25,165 & 26 & & & \\
\hline
\end{tabular}

Pode-se observar que a soma quadrática dos erros acaba tendo um valor acima do esperado, isso faz com que o modelo não descreva em sua totalidade, o que resulta em uma variação explicada de $77,6 \%$.

Analisando-se a Tabela 4, verifica-se que os termos quadráticos da concentração de extrato de levedura, $\mathrm{CaCO}_{3}$, temperatura e agitação e a interação entre os dois termos lineares (2) e (3) são significativos, como confirmado pelo $p$-valor $(0,05)$ apresentado.

Tabela 42. Cálculo dos efeitos e respectivos índices estatísticos para otimização.

\begin{tabular}{ccccc}
\hline & Efeito & Erro Padrão & $\begin{array}{c}\text { Teste } t \text { de } \\
\text { Student }\end{array}$ & Nível $p$ \\
\hline Média/Interações & $\mathbf{5 , 0 4 0}$ & $\mathbf{0 , 3 9 5}$ & $\mathbf{1 2 , 7 3 8}$ & $\mathbf{0 , 0 0 0 0}$ \\
(1) Ext. Levedura (L) & 0,325 & 0,279 & 1,164 & 0,266 \\
Ext. Levedura (Q) & $\mathbf{- 1 , 1 2 4}$ & $\mathbf{0 , 2 9 6}$ & $\mathbf{- 3 , 7 8 9}$ & $\mathbf{0 , 0 0 2}$ \\
(2) CaCO $(\mathrm{L})$ & 0,324 & 0,279 & 1,158 & 0,269 \\
CaCO $_{3}$ (Q) & $\mathbf{- 0 , 6 8 1}$ & $\mathbf{0 , 2 9 6}$ & $\mathbf{- 2 , 2 9 7}$ & $\mathbf{0 , 0 4 0}$ \\
(3) Temperatura (L) & 0,154 & 0,279 & 0,551 & 0,591 \\
Temperatura (Q) & $\mathbf{- 1 , 1 3 1}$ & $\mathbf{0 , 2 9 6}$ & $\mathbf{- 3 , 8 1 4}$ & $\mathbf{0 , 0 0 2}$ \\
(4) Agitação (L) & $-0,344$ & 0,279 & $-1,230$ & 0,242 \\
Agitação (Q) & $\mathbf{- 0 , 7 8 1}$ & $\mathbf{0 , 2 9 6}$ & $\mathbf{- 2 , 6 3 4}$ & $\mathbf{0 , 0 2 1 7}$ \\
Interação (2L) e (3L) & $\mathbf{- 0 , 7 4 8}$ & $\mathbf{0 , 3 4 2}$ & $\mathbf{- 2 , 1 8 5}$ & $\mathbf{0 , 0 4 9 4}$ \\
\hline
\end{tabular}

A Figura 3 apresenta os valores previstos versus observados, confirmando que o modelo proposto descreve parcialmente o fenômeno, visto que há uma dispersão dos pontos quando se busca um limite de confiança de $95 \%$. 


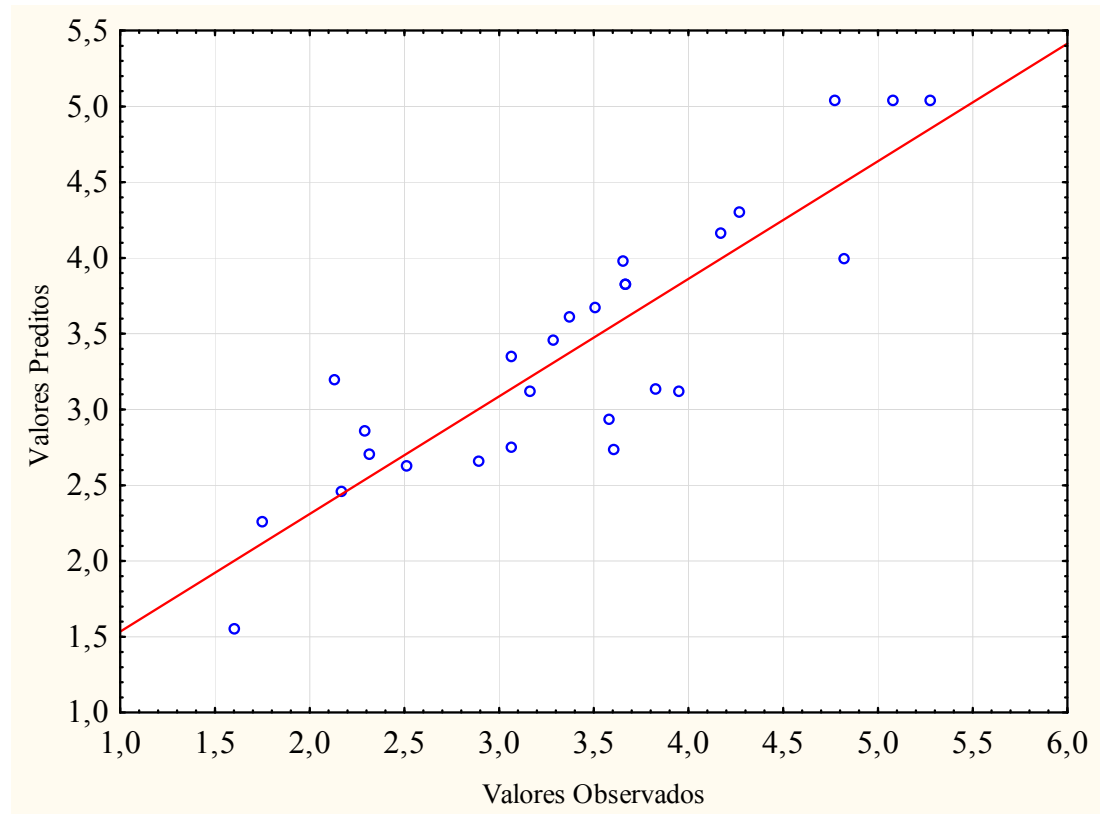

Figura 3. Valores preditos pelo modelo polinomial versus observados experimentalmente para a resposta do crescimento do Rhodococcus erythropolis.

A Figura 4 apresenta a região de máximo crescimento celular. Essa região ótima é definida no intervalo de concentração de $\mathrm{CaCO}_{3}$ de 0,8 a 1,2 g. $\mathrm{L}^{-1}$ (níveis - 0,5 a 0,5) e concentração de extrato de levedura de 5 a $7 \mathrm{~g} \mathrm{~L}^{-1}$ (níveis 0,5 a 0,5 ).

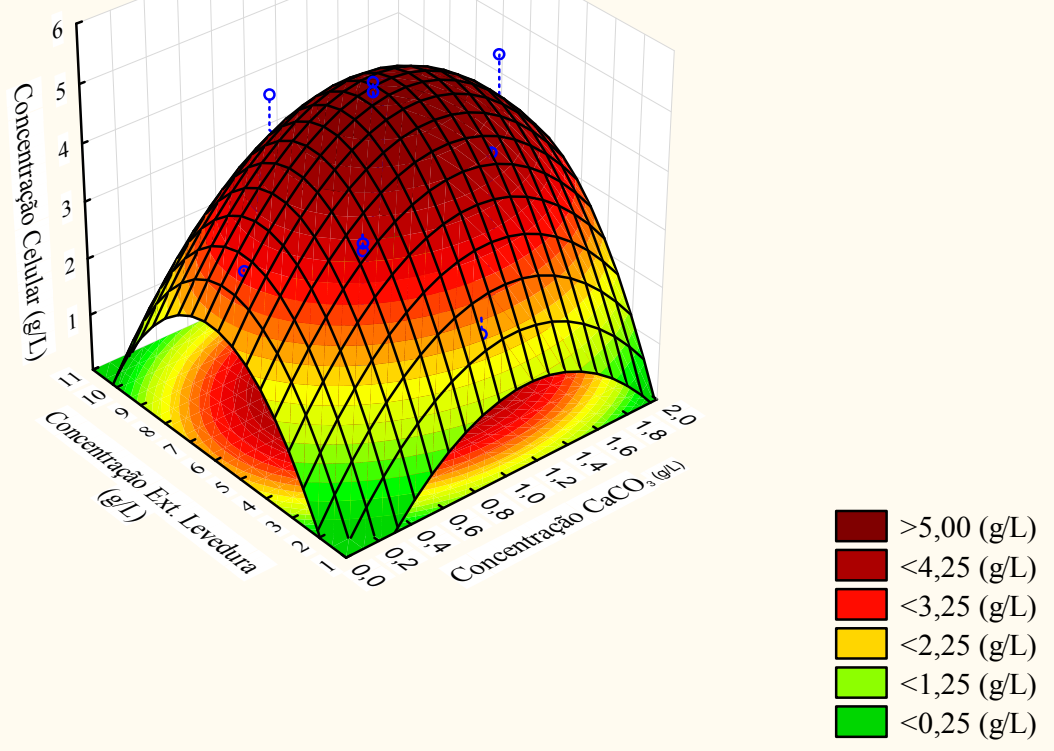

Figura 4. Superfície de resposta da concentração de $\mathrm{CaCO} 3$ versus extrato de levedura para o crescimento de Rhodococcus erythropolis.

Conforme mostra a Figura 5 verifica-se que a região ótima de crescimento encontra-se num nível máximo com agitação de 160 a $190 \mathrm{rpm}$ (níveis $-1,0$ a 0) e temperatura de 23,0 a $25^{\circ} \mathrm{C}$ (níveis $-0,5$ a 0,5 ). 


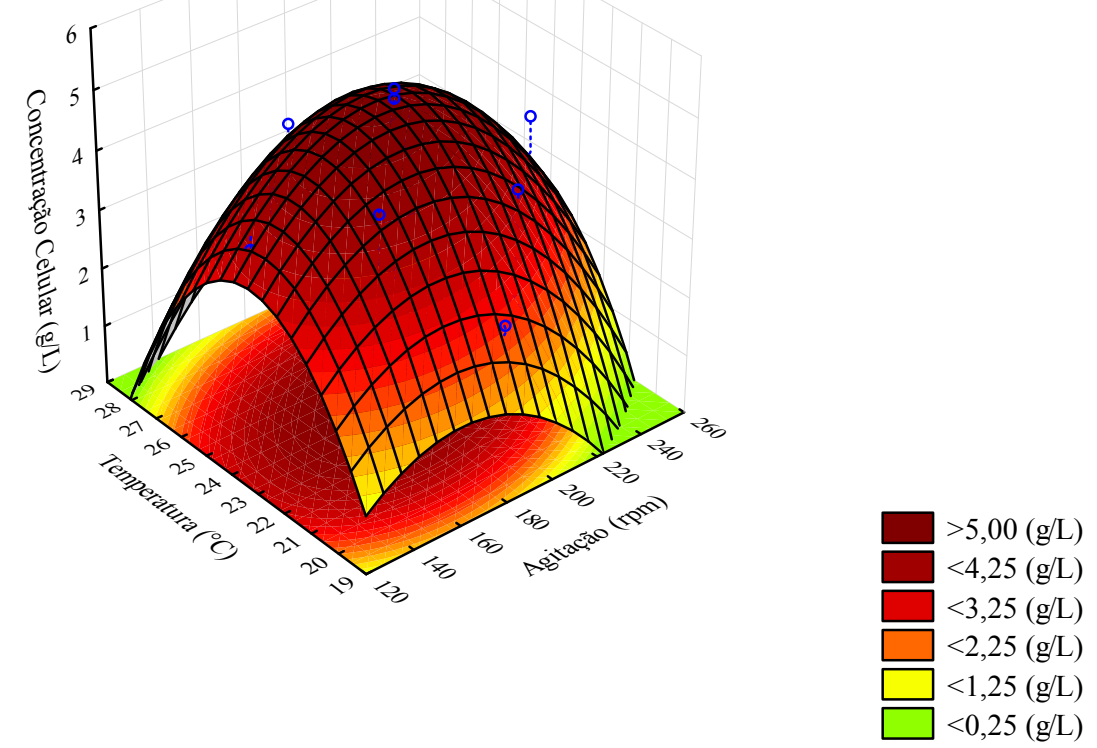

Figura 5. Superfície de resposta da agitação versus temperatura para o crescimento de Rhodococcus erythropolis.

Outro fato que pode ser observado nas curvas de nível das Figuras 4 e 5 é a maior sensibilidade para o crescimento do Rhodococcus erythropolis para a concentração de extrato de levedura e temperatura do que em relação à $\mathrm{CaCO}_{3}$ e agitação, fato que também pode ser visto pelo maior coeficiente dos mesmos.

O modelo para a o crescimento do Rhodococcus erythropolis é representado pela Equação 1:

$$
\begin{gathered}
C_{R . e .}=5,04-0,562187 A^{2}-0,340937 B^{2}-0,565937 C^{2} \\
-0,390937 D^{2}-0,374375 B C
\end{gathered}
$$

onde:

$C_{\text {R.e. }}=$ Concentração final de Rhodococcus erythropolis $\left(\mathrm{g} \mathrm{L}^{-1}\right)$;

$A=$ Concentração Extrato de levedura $\left(\mathrm{g} \mathrm{L}^{-1}\right)$;

$B=$ Concentração de $\mathrm{CaCO}_{3}\left(\mathrm{~g} \mathrm{~L}^{-1}\right)$;

$C=$ Temperatura $\left({ }^{\circ} \mathrm{C}\right)$;

$D=$ Agitação (rpm).

Foram determinados os pontos críticos ou estacionários, onde se tem o máximo de crescimento, 5,10 g.L $\mathrm{L}^{-1}$, que correspondem à concentração de extrato de levedura de 6,15 g.L $\mathrm{L}^{-1}$ (valor codificado 0,0759), concentração de $\mathrm{CaCO}_{3}$ 1,16 g.L - $^{-1}$ (valor codificado 0,4123 ), temperatura de $23,7^{\circ} \mathrm{C}$ (valor codificado $-0,1561$ ) e agitação de 180 rpm (valor codificado -0,3298). A diferença das cinéticas entre o meio inicial e otimizado são mostrados na figura 6 . 


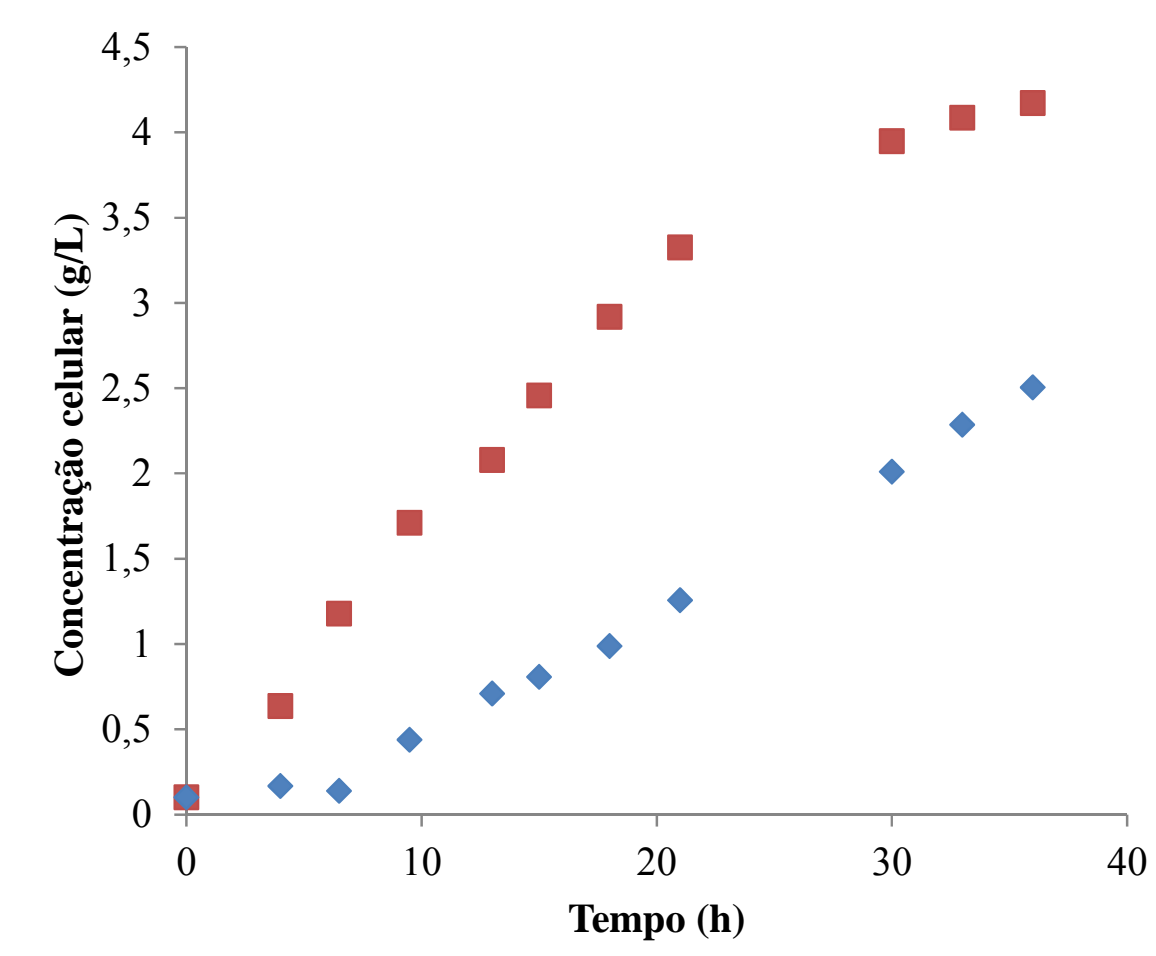

Crescimento celular meio Otimizado

Crescimento celular meio inicial

Figura 6. Cinéticas de crescimento do Rhodococcus erythropolis.

Através da Figura 6 é possível observar a redução da fase de adaptação do microorganismo que era de 8 a $10 \mathrm{~h}$ para 3 a $4 \mathrm{~h}$. Fator que pode ser destacado visto que facilita a sua utilização industrial, além de se obter uma maior velocidade de crescimento.

Com os resultado obtidos na otimização foi possível aumentar a eficiência do micro-organismo em relação ao crescimento celular e a quantidade de substrato presente no meio, adicionalmente o excesso de $\mathrm{CaCO}_{3}$ faz com que o micro-organismo não se desenvolva, já que sua adição faz com que se tenha uma elevação no $\mathrm{pH}$, conforme descrito por Maass (2011), o R. erythropolis se desenvolve em pH entre 6,5 e 7,5. Já a quantidade de oxigênio dissolvida tende a aumentar com a diminuição da temperatura e o aumento da agitação, segundo Pinotti (2003), devido à baixa solubilidade do oxigênio na água, é essencial à transferência contínua deste para o meio líquido de crescimento, visto que é um importante substrato em fermentações aeróbicas.

\section{CONCLUSÃO}

Neste trabalho realizou-se o estudo da influência de fatores como temperatura, agitação e concentrações dos compostos: extrato de levedura, $\mathrm{CaCO}_{3}$ no crescimento do micro-organismo Rhodococcus erythropolis ATCC4277. Os valores encontrados para a concentração de extrato de levedura e temperatura apresentaram uma maior influência no crescimento do Rhodococcus erythropolis quando comparados com a $\mathrm{CaCO}_{3} \mathrm{e}$ agitação. Com a otimização do meio de crescimento foi possível reduzir a fase lag que era de 8 a $10 \mathrm{~h}$ para 3 a $4 \mathrm{~h}$.

Este trabalho permite a minimização da realização de ensaios experimentais, priorizando o estudo de variáveis relevantes no processo, além de obter mais 
informações sobre o efeito de cada variável junto ao crescimento do Rhodococcus erythropolis.

\section{REFERÊNCIAS}

CARVALHO, C. C. C. R.; da FONSECA, M. M. R. The remarkable Rhodococcus erythropolis. Appl. Microbiol. Biot., v. 67, p. 715-726, 2005.

DINAMARCA, M. A.; IBACACHE-QUIROGA, C.; BAEZA, P.; GALVEZ, S.; VILLARROEL, M.; OLIVERO, P.; OJEDA, J. Biodesulfurization of gas oil using inorganic supports biomodified with metabolically active cells immobilized by addsorpion. Bioresource. Technol. V. 101, p. 2375-2378, 2010.

DINAMARCA, M. A.; ROJAS, A.; BAEZA, P.; ESPINOZA, G.; IBACACHEQUIROGA, C.; OJEDA, J. Otimizing the biodesulfurization of gas oil by adding surfactants to immobilized cell systems. Fuel. V. 116, p. 237-241, 2014.

HUANG, L.; MA, T.; LI, D.; LIANG, F. L.; LIU, R. L.; LI, G. Q. Optimization of nutrient component for diesel oil degradation by Rhodococcus erytrhopolis. Mar. Pollut. Bull. V. 56, p. 1714-1718, 2008.

MAASS, D.; Dessulfurização do DBT e do óleo diesel em sistema bifásico pelo Rhodococcus erythropolis ATCC 4277 em reator descontínuo. Dissertação de Mestrado.

Universidade Federal de Santa Catarina. Florianópolis, 2011.

PINOTTI, L. Study of different media for production of penicillin G Acylase from Bacillus magaterium ATCC 14945. Appl. Biochem. Biot., v. 84 (6), p. 655-663, 2000.

SANCHEZ, N.; SANDOVAL, A. H.; DIAZ-CORRALES, F.; SERRANO, J. A. Revista de la sociedade venezolana de microbiologia. Caracas, 2004.

TORRES, S.; PANDEY, A.; CASTRO, G. R. Organic solvente adaptation of gram positive bacteria: Applications and biotechnological potentials. Biotechnol. Adv., v. 29, p. 442-452, 2011.

VAIDYA, B. K.; MUTALIK, S. R.; JOSHI, R. M.; NEME, S. N.; KULKARNI, B. D. Enhanced production of amylase from Rhodococcus erythropolis MTCC 1526 by medium optimization using a statistical experimental design. J. Ind. Microbiol. Biotechnol. V. 36, p. 671-678, 2009. 